\title{
Morphometric studies of the mandibular and maxillofacial regions of the Kuri cattle and the implications in regional anaesthesia
}

\author{
B.G. Gambo1, A. Yahaya1', I. Girgiri', J.O. Olopade² \\ ${ }^{1}$ Department of Veterinary Anatomy, Faculty of Veterinary Medicine, University of Maiduguri, Nigeria \\ ${ }^{2}$ Department of Veterinary Anatomy, Faculty of Veterinary Medicine, University of Ibadan, Nigeria
}

[Received 23 March 2014; Accepted 21 October 2014]

This work investigated and analysed some morphometrical measurements of mandibles and maxillofacial regions of ten adult Kuri cattle (above 5 years) skulls that were apparently free from musculoskeletal deformity. A total of 19 (13 mandibular and 6 maxillofacial) parameters were taken. The mean mandibular length and height were found to be $41.3 \pm 2.35 \mathrm{~cm}$ and $22.6 \pm 1.40 \mathrm{~cm}$, while the mean mental foramen height and width were $0.8 \pm 0.08 \mathrm{~cm}$ and $1.5 \pm 0.25$ $\mathrm{cm}$, respectively. The mean distances from lateral alveolar root to mental foramen and from the latter to the most caudal border of the mandible were $4.8 \pm 0.61$ $\mathrm{cm}$ and $34.2 \pm 1.93 \mathrm{~cm}$, respectively. The mean mandibular foramen width was $1.1 \pm 0.14 \mathrm{~cm}$, while the distance from this foramen to the caudal border of mandible at that level was $4.0 \pm 0.32 \mathrm{~cm}$. The mean distances from facial tuberoses to the infraorbital foramen and from the latter to the alveolar root ventral to it were $5.3 \pm 0.63 \mathrm{~cm}$ and $3.7 \pm 0.47 \mathrm{~cm}$, whereas the mean infraorbital foramen height and width stood at $1.2 \pm 0.18 \mathrm{~cm}$ and $1.0 \pm 0.22 \mathrm{~cm}$, respectively. The infraorbital foramens in $60 \%$ of the specimen were located above the first upper premolar, while 20\% were above second premolar, and another 20\% at the junction above first and second upper premolars. These findings provide important landmarks needed for clinical manoeuvres on the head of the Kuri cattle for regional anaesthesia in procedures like trephination, dehorning, tooth extraction and oral and dental surgeries. (Folia Morphol 2015; 74, 2: 183-187)

Key words: morphometry, mandible, maxillofacial, Kuri cattle, regional anaesthesia

\section{INTRODUCTION}

The Kuri (Buduma, White lake cattle) breed of cattle is of the Hamitic longhorn (Bos taurus longifrons) which is predominantly found on the islands and along the shorelines of the Lake Chad, as their natural habitat, which is formed by the 4 neighbouring countries of Cameroon, Chad, Niger, and Nigeria. Several authors put the Kuri population within the range of 100-400 thousand, but the actual population sizes of the Kuri cattle is not precisely known. However it has been suggested that the breed is vulnerable because of its localised and special, but shrinking habitat [11]. The Kuri is believed to be one of the tallest breed of cattle of African origin standing about $180 \mathrm{~cm}$ tall at withers and bulls weights ranging 360-750 kg $[4,2,9]$.

Kuri cattle are excellent swimmers, and usually spend considerable time of the day immersed in Lake

Address for correspondence: Prof. J.O. Olopade, Department of Veterinary Anatomy, Faculty of Veterinary Medicine, University of Ibadan, Nigeria, tel: +23408023860829, e-mail: jkayodeolopade@yahoo.com 
Chad water [2]. The striking and unique characteristic of this breed is the bulbous horns with spongy interior and very thin external shell, an adaptive characteristic required to survive in the natural aquatic environment of the Lake Chad $[2,4]$. They are usually allowed to graze freely and return home on their own at sunset [11].

The basic knowledge of morphometry of the mandibular and maxillofacial regions are important in veterinary clinical practice since the different foramina of these regions are of clinical importance in regional anaesthesia for surgical procedures such as oral and dental surgery, trephination of caudal frontal and maxillary sinuses, and dehorning. These basic baseline craniometric indices are, however, rarely available in literature for the Kuri cattle.

The aim of this study is to document maxillofacial and mandibular morphometric measurements of the Kuri that may be important for regional anaesthesia

\section{MATERIALS AND METHODS}

A total of ten adult Kuri cattle (above 5 years) were used for this study. All animals used were physically examined for their state of health and particularly, for absence of musculoskeletal deformities. Their estimated ages were determined based on dental eruption technique [8]. The heads of the animals were obtained immediately after slaughter from 2 abattoirs of Lagos and Ibadan. Each head was decapitated at the occipito-atlantal joint and the skulls were processed by hot water maceration techniques as described by previous authors $[7,12]$.

A total of 19 (13 mandibular and 6 maxillofacial) parameters were determined on each skull with the aid of metric rules, Vernier callipers and a pair of dividers and compasses. Mandibular and maxillary parameters were adopted from the reports of Olopade and Onwuka [7], and Monfared [5, 6]. Vital morphological landmarks in the mandibular and maxillofacial regions that would be important for tracking of foramina were described. Metric parameters of the mandible and maxillofacial bones of the Kuri cattle are described below in order arranged in Figures 1-4. - Lateral alveolar root to mental foramen (LARM):

Distance from the caudal end of the lateral alveolar root to the mid-rostral brim of the mental foramen (Fig. 1).

- Mental foramen to caudal mandibular border (MFCM): Distance from the mid-caudal brim of the mental foramen to the most caudal border of the mandible (Fig. 1).

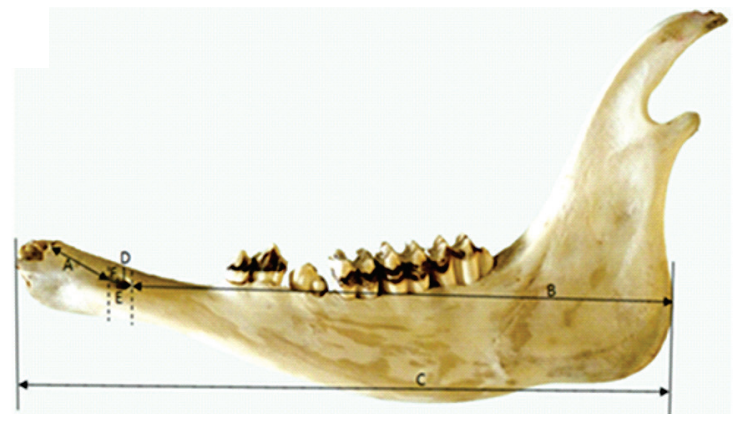

Figure 1. Lateral view of the mandible of the Kuri cattle; A - lateral alveolar root to mental foramen (LARM); B - mental foramen to caudal mandibular border (MFCM); $\mathrm{C}$ - mandibular length (MDL); D - mental foramen to diastema (MBMD); E - mental foramen height (MFH); $\mathrm{F}$ - mental foramen width (MFW).

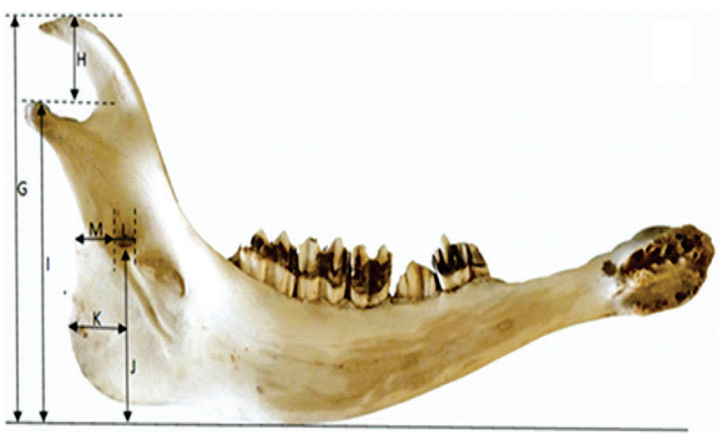

Figure 2. Medial view of the mandible of Kuri cattle; $G$ - Mandibular height (MHMD); $\mathrm{H}$ - maximum height to condyloid fossa (MHCF); I - base of mandible to condyloid fossa (BMCF); J mandibular foramen to base of mandible (MDFB); $\mathrm{K}$ — caudal border to vertical line (CBMV); $L$ - mandibular foramen width (MDFW); $\mathrm{M}$ - mandibular foramen to caudal mandibular border. (MDFCB).

- Mandibular length (MDL): From the level of the cranial extremity of the alveolar root of the lower incisors to the level of the caudal border of the mandible (Fig. 1).

- Mental foramen to diastema (MBMD): Distance from mid-dorsal brim of mental foramen to directly dorsal to the line of diastema (Fig. 1).

- Mental foramen height (MFH): Distance from the mid-dorsal margin to mid-ventral margin of the mental foramen (Fig. 1).

- Mental foramen width (MFW): Distance from the mid-rostral margin to mid-caudal margin of the mental foramen (Fig. 1).

- Maximum height of mandible (MHMD): From the basal level of the mandible to the highest level of the coronoid process (i.e. BMCF $+\mathrm{MHCF}$ ) (Fig. 2). 


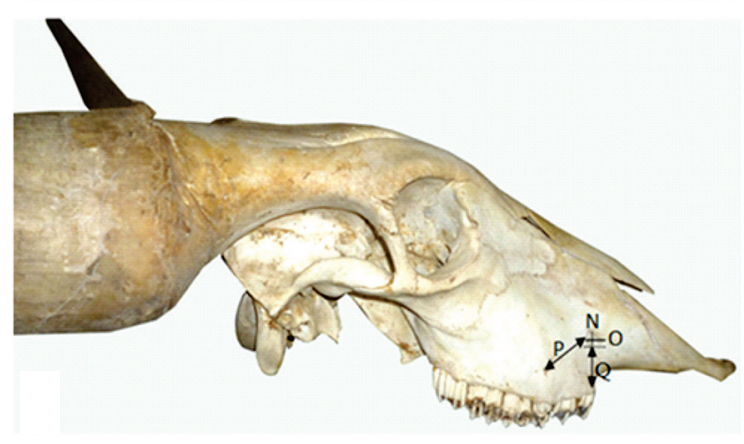

Figure 3. Lateral view of the skull of Kuri cattle; $\mathrm{N}$ - infraorbital foramen height (IOFH); 0 - infraorbital foramen width (IOFW); $\mathrm{P}$ - facial tuberoses of infraorbital foramen (FTIOF); 0 - infraorbital foramen to root of alveolar tooth (IFRAT).

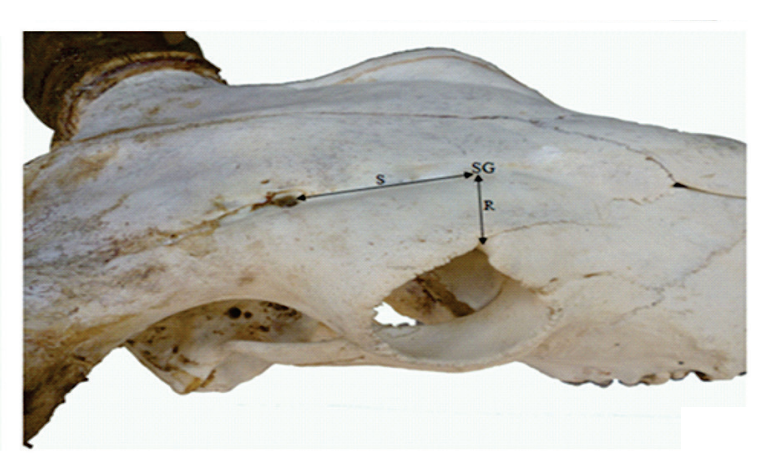

Figure 4. Dorso-lateral view of the skull of Kuri cattle; $\mathrm{R}$ - mid-dorsal brim of the orbit to a point "SG" in the supraorbital groove (DMOSG); S - supraorbital point "SG" caudally to supraorbital foramen (SGSOF).

- Maximum height to condyloid fossa (MHCF): Distance from the condyloid fossa to the maximum height of the coronoid process (Fig. 2).

- Base of mandible to condyloid fossa (BMCF): Distance from the base of mandible to the condyloid fossa (Fig. 2).

- Mandibular foramen to base of mandible (MDFB): Vertical line from the ventral limit of the mandibular foramen to the base of the mandible (Fig. 2).

- Caudal border of mandible to vertical line (CBMV): Distance from the most caudal border of mandible to the vertical line produced by MDFB above (Fig. 2).

- Mandibular foramen width (MDFW): Distance between the rostral and caudal margins of the mandibular foramen at the middle (Fig. 2).

- Mandibular foramen to caudal mandibular border (MDFCB): From mid-caudal brim of the mandibular foramen to the caudal border of the mandible directly caudal to it (Fig. 2).
- Infraorbital foramen height (IOFH): The distance between the dorsal and ventral margins of the infraorbital foramen at its widest point (Fig. 3).

- Infraorbital foramen width (IOFW): Distance between the rostral and caudal margins of the infraorbital foramen at the middle (Fig. 3).

- Facial tuberoses to infraorbital foramen (FTIOF): From the level of the most lateral bulging of the facial tuber to mid-caudal margin of the infraorbital foramen (Fig. 3).

- Infraorbital foramen to root of alveolar tooth (IFRAT): Measurement is from the level of mid-ventral margin of the infraorbital foramen to the root of alveolar tooth directly ventral to it (Fig. 3).

- Mid-dorsal margin of the orbit to supraorbital groove (DMOSG): Measurement from the lateral aspect of the mid-dorsal margin of the orbit to supraorbital groove point "SG" (Fig. 4).

- Supraorbital groove to supraorbital foramen (SGSOF): Distance from the point "SG" produced in supraorbital groove caudally to supraorbital foramen (Fig. 4).

All data obtained were statistically analysed using Statistical Package for Social Sciences (SPSS) version 17 and presented as mean \pm standard deviation.

\section{RESULTS AND DISCUSSION}

The metric data obtained in this study are tabulated in Table 1. The mandibular length and height were found to be $41.3 \pm 2.35 \mathrm{~cm}$ and $22.6 \pm 1.40 \mathrm{~cm}$, while the mental foramen height and width were $0.8 \pm 0.08 \mathrm{~cm}$ and $1.5 \pm 0.25 \mathrm{~cm}$, respectively. The distances from lateral alveolar root to mental foramen and from the latter to the most caudal border of the mandible were $4.8 \pm 0.61 \mathrm{~cm}$ and $34.2 \pm 1.93 \mathrm{~cm}$, respectively. The mandibular foramen width was $1.1 \pm 0.14 \mathrm{~cm}$, while the distance from this foramen to the caudal border of mandible at that level was $4.0 \pm 0.32 \mathrm{~cm}$. The distances from facial tuberoses to the infraorbital foramen and from the latter to the alveolar root ventral to it were $5.3 \pm 0.63 \mathrm{~cm}$ and $3.7 \pm 0.47 \mathrm{~cm}$, whereas the infraorbital foramen height and width stood at $1.2 \pm 0.18 \mathrm{~cm}$ and $1.0 \pm 0.22 \mathrm{~cm}$, respectively. The infraorbital foramens in $60 \%$ of the specimen were located above the first upper premolar, while $20 \%$ were above second premolar, or at the junction above first and second upper premolars.

The knowledge of mandibular and maxillofacial anatomy is important for regional anaesthesia of the head for trephination, dehorning, dental surgery and 
Table 1. Mean \pm standard deviation (SD) measurements of mandibular and maxillofacial parameters of the Kuri cattle

\begin{tabular}{lc}
\hline Morphometric parameter [cm] & Mean \pm SD \\
\hline LARM & $4.8 \pm 0.61$ \\
MFCM & $34.2 \pm 1.93$ \\
MDL & $41.3 \pm 2.35$ \\
MBMD & $0.9 \pm 0.20$ \\
MFH & $0.8 \pm 0.08$ \\
MFW & $1.5 \pm 0.28$ \\
MHMD & $22.6 \pm 1.40$ \\
MHCF & $5.4 \pm 0.43$ \\
BMCF & $17.2 \pm 1.20$ \\
MDFB & $9.0 \pm 0.97$ \\
CBMV & $4.3 \pm 0.72$ \\
MDFW & $1.1 \pm 0.14$ \\
MDFCB & $4.0 \pm 0.32$ \\
IOFH & $1.2 \pm 0.18$ \\
IOFW & $1.0 \pm 0.22$ \\
FTIOF & $5.3 \pm 0.63$ \\
IFRAT & $3.7 \pm 0.47$ \\
DMOSG & $3.1 \pm 0.45$ \\
SGSOF & $8.8 \pm 1.08$ \\
\hline
\end{tabular}

Abbreviations - see the text

other oral cavity procedures. In this study, the distance from lateral alveolar tooth root to the mental foramen and the latter to caudal mandibular border in the adult Kuri cattle were $4.8 \mathrm{~cm}$ and $34.2 \mathrm{~cm}$, while the corresponding value in the Iranian native cattle were reported to be $5.7 \mathrm{~cm}$ and $23.8 \mathrm{~cm}$ [5], and in Iranian buffaloes $-6.0 \mathrm{~cm}$ and $24.1 \mathrm{~cm}$, respectively [6]. This variation could probably be linked to the skull sizes of these breeds. These data therefore, are of clinical relevance in mental nerve block to aid surgical procedure on the lips, lower incisors, and alveoli of premolar teeth of the corresponding half [3].

The lengths from the mandibular foramen to the base of the mandible and from the former directly to the caudal mandibular border were $9 \mathrm{~cm}$ and $4 \mathrm{~cm}$, respectively. The value from the most caudal border of the mandible to the imaginary line produced by mandibular foramen to base was $4.3 \mathrm{~cm}$. These data together with the mandibular foramen width of $1.1 \mathrm{~cm}$ in the adult Kuri cattle will serve as a landmark for mandibular nerve block which will result in desensitisation of the entire dental arcades and the surrounding structures of the corresponding half (without skin, subcutaneous and muscle tissues) of the injected site [7].

The facial tuberoses were found to be prominent even in the live animals; this would aid in locating the infraorbital foramen. The mean distance from facial tuberoses to infraorbital foramen and from the latter to the root of alveolar tooth ventral to it were $5.3 \mathrm{~cm}$ and $3.7 \mathrm{~cm}$, respectively; together with the infraorbital foramen height and width of $1.2 \mathrm{~cm}$ and $1 \mathrm{~cm}$ would serve as a vital guide to track the infraorbital nerve for the desensitisation of the nostrils, skin of the lips and the face around the foramen of the side [7]. The infraorbital foramen is mostly located directly dorsal to the first upper premolar and in some instances above the second premolar, and at a junction above first and second upper premolar teeth, while in the Iranian native cattle and Pakistan buffaloes are located above the first premolar, as reported by Monfared [5, 6] and Shahid and Muhammad [10]. However, Olopade and Onwuka [7] reported it to be dorsal to the second premolar or junction of the first and second upper premolar in the West African dwarf goat.

In trephination of frontal sinus and dehorning procedures, supraorbital nerve block is necessary. Cornual nerve block alone is not always successful in dehorning procedure; this is because of the substantial contributions from the supraorbital nerve, which extends from the frontal sinus to the diverticulum within the horn [1]. Taking a measurement from mid-dorsal margin of the dorsal arch of the orbit to the supraorbital groove and from the latter point caudally to the supraorbital foramen $(3.1 \mathrm{~cm}$ and $8.8 \mathrm{~cm}$, respectively in this study) will facilitate the tracking of the supraorbital nerve in the adult Kuri cattle. To the best of our knowledge, there is no previous information on the provision of this landmark in any other cattle breed to which could be compared.

\section{CONCLUSIONS}

The findings presented above will serve as vital baseline data on morphometry of mandibular and maxillofacial regions of the Kuri cattle to which comparisons could be made with other breeds of cattle found in the region and beyond. Also, it would aid regional analgesia of these areas as efforts are geared towards treating common clinical cases such as dehorning, and doing procedures like trephination of frontal sinus, and dental surgeries to relieve animal suffering and improve livestock subsector. 


\section{ACKNOWLEDGEMENTS}

The authors would like to acknowledge the contributions of M.A. Buhari, Dr. I.O. Fatola, and Dr K.A. Sanda for skull preparation and data processing.

\section{REFERENCES}

1. Dyce KM, Sack WDO, Wensing CJG (2010) Text book of veterinary anatomy. $4^{\text {th }}$ Ed. Saunders Elsevier, China, pp. 644-663.

2. Epstein $H$ (1971) The origin of the domestic animals of Africa. Vol. 1, 2. Publ Africana, New York.

3. Hall LW, Clarke KW, Trim CM (2000) Wright's veterinary anaesthesia and analgesia. $10^{\text {th }}$ Ed. ELBS and Baillierre Tindall, London.

4. Malbrant R, Receveur P, Sabin R (1947) Le boeuf du lac Tchad. Rev Elev Med Vet Pays Trop, 1: 109.

5. Monfared AL (2013a) Gross anatomical measurements of the head region of the Iranian Native Cattle (Bos taurus) and their clinical value for regional anesthesia. Global Veterinaria, 10: 219-222.

6. Monfared AL (2013b) Gross anatomical studies on the skull of the Iranian Native Buffaloes and their clinical value for regional anesthesia. Global Veterinaria, 10: 427-431.

7. Olopade JO, Onwuka SK (2005) Some aspect of the clinical anatomy of the mandibular and maxillofacial regions of West African dwarf goat in Nigeria. Int J Morphol, 23: 33-36.

8. Pasquini C (1982) Atlas of Bovine Anatomy. Sudz Publishing Eureka, California.

9. Queval R, Petit JP, Tacher G, Provost A, Pagot J (1971) Le Kouri. race bovine du lac Tchad. I, Introduction generale a son etude zootechnique et biochimique: Origins et ecologie de la race. Rev Elev Med Vet Pays Trop, 24: 667-687.

10. Rashid RU, Muhammad F (2001) Comparative gross anatomical study of the axial skeletons of buffaloes and cows. Pakistan Vet J, 21: 55-56.

11. Tawah CL, Rege JEO, Aboagye GS (1997) A close look at a rare African breed-the Kuri cattle of Lake Chad Basin: origin, distribution, production and adaptive characteristics. South African J Animal Science, 27: 31-40.

12. Yahaya A, Olopade JO, Kwari HD (2011) Clinical implications of craniometric indices of the one-humped camel (Camelus dromedaries) to oral health and clinical regional anaesthesia of the head. J Vet Anat, 4: 19-31. 